\title{
Problem solving, exercises and explorations in mathematics textbooks: \\ A historical perspective
}

\author{
João Pedro da Ponte \\ Instituto de Educação, Universidade de Lisboa
}

\begin{abstract}
This paper analyses the tasks proposed in several Portuguese mathematics textbooks, from the $19^{\text {th }}$ to the $21^{\text {st }}$ century. A look at the nature and intended purpose of these tasks raises interesting issues about school mathematics teaching and learning. Has the meaning of terms such as "problem" and "exercise" been always the same? What other terms have been used in textbooks to designate mathematics tasks? What were the reasons for the changes? The analysis of the evolution that occurred in the terminology as well as in the nature of the tasks proposed to the students provides elements to reflect about what the changes that have occurred in mathematics teaching and learning and how some changes are more apparent than real.
\end{abstract}

\section{Introduction}

History stimulates a broad view of social processes and a deep understanding of educational questions. As a secondary school student I always maintained a high interest in historical issues which I kept and developed as a mathematics educator. When I took a position at the University of Lisbon, in 1980, after six years as a secondary school mathematics teacher, I had some difficulty in figuring out my own academic identity. As the single mathematics educator at the university I had no colleagues to discuss the content and meaning of my new job, I looked at recent history striving to understand what had happened in the former period in field of mathematics education, both in the international setting and in my own country. At the time, the major influence in the curriculum was modern mathematics. Therefore, some questions that I struggled with were: What provided the impetus for this movement? What were its main ideas? How those ideas did got translated in the curriculum? And in school mathematics teaching and learning? What led this movement to decline? As a graduate student at the University of Georgia, shortly after, I become a student of Jeremy Kilpatrick who participated in this period and could present a firsthand account of the events and the forces behind them.

Besides modern mathematics, I was always intrigued by what happened before. The paper by Jeremy Kilpatrick (1992), about the history of research in mathematics education in the USA not only provided a look going back much earlier, but it also provided a very comprehensive view the elements that contributed in the development 
of our field. This helped me to overcome my fragmented view, understanding the relations of mathematics education with mathematics and psychology, its place at the university, the emergence of the professional domain of mathematics education, and its consolidation as an academic community.

As a secondary school mathematics teacher and later as a mathematics teacher educator, I also developed a high interest in problem solving. I was always fond of investigating mathematics issues, striving to understand relationships at a deeper level. As a teacher educator, I addressed questions such as what were fruitful problems to propose to students at different school levels and how to work them in the classroom (e.g., Ponte \& Abrantes, 1982). The reading of the paper by Stanic and Kilpatrick (1989), with a historical perspective on problem solving in the mathematics curriculum was an enlightening experience. I could see the important role of problems in school mathematics, from ancient to contemporary times. And I also could see how an insightful analysis of the thinking of two outstanding scholars - John Dewey and George Pólya - may provide the ground for a deeper understanding of different ways of using problems in teaching and learning.

As a graduate student working with the supervision of Jeremy Kilpatrick I learned a lot from him in many fields, such as research methods, student learning, assessment, curriculum theory, and teacher education. Perhaps the most important learning concerned the ways of framing questions in mathematics education and pursuing disciplined inquiry into them, considering different viewpoints, weighting evidence, and framing conclusions in a clear and convincing way.

The role of algebra in the school curriculum is another object of attention of Jeremy (Kilpatrick \& Izsák, 2008). In the 2000s, I become increasingly interested in the teaching of algebra. In Portugal, as in other countries, after the strong algebraization of the curriculum in the modern mathematics period, this topic just disappeared as a central curriculum strand. Of course, there were still equations and functions in the curriculum, but algebra was no longer a main organizing idea of the curriculum - and the students did not even come across with this term. Besides studying the emergent literature on algebraic thinking and early algebra, I took a look on the teaching of algebra in former periods. In a first paper (Ponte, 2004) I sought to identify aspects that changed in the approach of $1^{\text {st }}$ degree equations in Portuguese textbooks in the period of a century. For that purpose I took a textbook from the end of the $19^{\text {th }}$ century, other from the middle of $20^{\text {th }}$ century, other from modern mathematics (the 1970s) and one contemporary (the 
1990s). The analysis shows an interesting evolution driven by the ideas of "starting earlier" and "simplifying", providing room for teaching other topics. With modern mathematics the notation and approach had a significant change, but afterwards, with some additional simplification, they went back to something quite similar to what was before. In another paper (Ponte, Salvado, Fraga, Santos, \& Mosquito, 2007) I made a similar analysis regarding how $2^{\text {nd }}$ degree equations are presented in seven school mathematics Portuguese textbooks. The analysis also shows that the approach is increasingly simplified in its content, in the tasks proposed to the students, and in the language. Doing this analysis I noticed interesting contrasts in the tasks proposed to the students at the end of the chapters. Therefore, in this paper, I choose to combine several of these strands - history of mathematics education, problem solving, algebra and student learning - and discuss the evolution of mathematics tasks proposed in mathematics textbooks.

\section{A framework to analyse mathematics tasks}

Pólya (1957) makes a distinction between routine and non-routine mathematical problems. In his view, a routine problem (or "exercise") can be solved by using a general method, given in abstract terms or by practicing a variety of examples. In contrast, a non-routine mathematical problem (or just "problem") requires the use of some judgment or inventive faculty. More recently, Stein and Smith (1998) present another framework for mathematical tasks based on the presupposed cognitive complexity and also in the possible establishment of connections. They classify tasks as having low or high cognitive demand, the first including "memorization tasks" and "procedures with no connections" and the second including "procedures with connections" and "doing mathematics". The framework of the PISA study (OCDE, 2004) refers to three different kinds of tasks, also classified according to their level of cognitive demand - reproduction, connection, and reflection. However, we must note that it is impossible to classify a task just by itself, since its meaning is always relative to the person that is to solve it. In fact, a task may be a difficult problem for a given person and just a simple exercise for another person. When we speak of the cognitive demand of a task, we always have in mind the "typical" student to whom it will be proposed. 
Besides familiarity with a solution method and cognitive demand, there are other dimensions in which tasks may be classified. For example, the context may be purely mathematical, or framed in terms of other school subjects or experiential fields. In this regard, Skovsmose (2001) makes an interesting distinction between tasks that have a "real-life" reference, which involve the real data collected from experience, and "semireality", in which the statement corresponds to an abstracted, simplified, and often stereotyped situation that is framed just for school purpose. Another distinction that may be made regards the nature of the representations involved. For examples, the task may be framed in a very symbolic and abstract way, with almost no natural language, may require extensive interpretation of text, may involve other representations as images or diagrams, and may require the use of several representations and possibly of conversion of representations.

Exercises, explorations, problems, and investigations may be regarded as different kinds of mathematical tasks according to the degree of structure and to the level of cognitive demand - which I prefer to refer to as degree of challenge (Ponte, 2005). The exercise is, by far, the most characteristic task in mathematics. Pólya (1957) made a strong case for the idea that, besides exercises, students should also have the opportunity to get involved in solving problems. His distinction between exercise and problem become a key idea in mathematics education. As a consequence, in many countries, everything that is not seen as an exercise is often called a "problem". However, the interest in considering different tasks with specific purposes suggests the need for a refinement of the language. The terms "investigation" and "exploration" are increasingly being used to name tasks that have some element of openness in the aim, the givens, and/or the possible interpretations. It is interesting to note how often these two terms appear in professional journals such as the Mathematics Teacher and Teaching Mathematics in the Middle School as well as the decision of the NCTM to rename the Students' Math Notes as Students' Explorations. Similarly to problem solving, when students are involved in exploring and investigating mathematics, they do not have an immediate strategy to use and the first step is to make sense of the task in order to design a strategy to deal with it. Sometimes the two terms are used interchangeably, but often "investigations" carry the idea of being more complex and “explorations" more accessible (Figure 1).

High complexity 


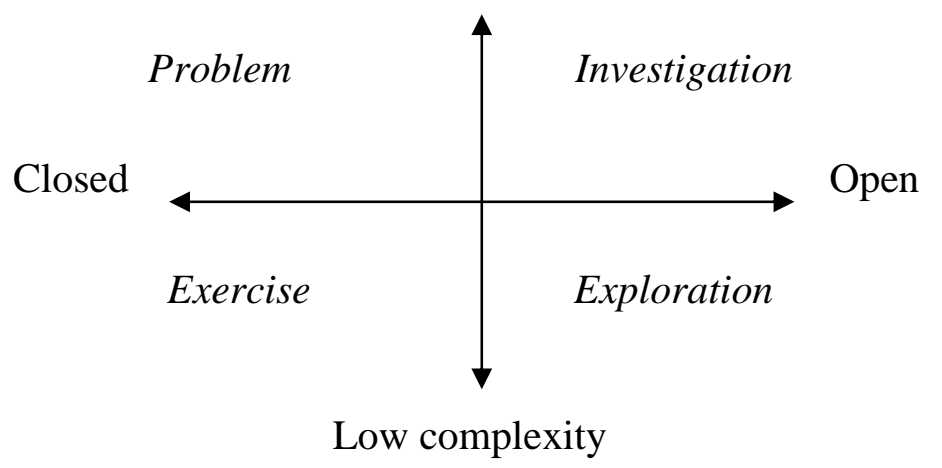

Figure 1 - Different kinds of tasks, in complexity (vertical dimension) and structure (horizontal dimension).

In this paper I focus the attention in the degree of challenge of tasks as well as to the underlying context, the language and representations that are used to frame them, and the thinking the processes involved. And I also look to the way tasks themselves are presented in textbooks.

\section{Mathematical tasks in algebra textbooks of different periods}

In this section, I look at six different algebra textbooks, from different periods. In every textbook I pay special attention to the tasks proposed to the students related to the topic of $2^{\text {nd }}$ degree equations. The focus on a single topic is useful to provide a contrast on the dimensions that we look at.

\subsection{Augusto José da Cunha Cunha (1887). Elementos de Álgebra (Elements of} Algebra). This textbook, with 338 pages, written by a higher education professor (Polytechnical School), aimed at 13-14 years old lyceum students. It is divided in five “books", with book III devoted to $2^{\text {nd }}$ degree equations (52 pp.). This book includes four chapters, dealing with $2^{\text {nd }}$ degree roots (16 pp.), $2^{\text {nd }}$ degree equations with one unknown (26 pp.), equations that may be reduced to the $2^{\text {nd }}$ or the $1^{\text {st }}$ degree $\left(14\right.$ pp.) and $2^{\text {nd }}$ degree problems (10 pp.). At the end of each chapter there are exercises and solutions.

Chapter IV is devoted to solving three problems, one from geometry (dividing a line in two parts in some ratio) and two from physics (speed of sound in the context of a well and finding a point illuminated with equal intensity by two bulbs). The problems are first translated from natural to algebraic language, yielding $2^{\text {nd }}$ degree equations, 
then solved with the procedures described in the previous chapters, and finally discussed.

At the end of the first three chapters there are exercises such as: "Solve the following equations"; "Decompose the trinomial in two first degree factors"; "Find the square root of the polynomial"; "Simplify the expression"; and "Prove the following equalities (figure 2). All exercises proposed, starting with exercise 1, are highly structured and complex. At the end of chapter IV, the textbook presents eight problems to solve (figure 3): four geometrical, two numeric (involving relationships among different numbers), one arithmetic sequence, and another a daily life situation. Solutions are given for almost all exercises.

\section{EXERCICES}

Solve the following equations :

I. $\frac{2 x-3}{x-3}=\frac{5 x-4}{x}-\frac{3}{2}$

II. $\frac{1}{x-1}+\frac{1}{x-2}=\frac{1}{x-3}$

$(\ldots)$

$\mathrm{XIV} \cdot \frac{x^{2}}{\sqrt{a}+\sqrt{b}}-(\sqrt{a}-\sqrt{b}) x=\frac{\sqrt{a^{3} b^{3}}}{\sqrt{\bar{a}^{2} b}+\sqrt{a b^{2}}}$

XVI. Decompose the trinomial in two fist degree factors

$3 x^{2}+\frac{3 a^{2}-4 b^{2}}{2 a b} x-1$

Figure 2 - The first two and two of the last exercises of chapter II.

\section{EXERCICES}

I. Find five numbers in arithmetic progression so that their sum is 35 and their product is 10395.

VIII. Two asylums distributed, each one, $120 \$ 000$ reals of donations. The first assisted 40 poor man more than the second; however, this one gave to each poor man 500 reals more than the first. Haw many poor man were assisted by each asylum?

Figure 3 - The first and the last problems of chapter IV (indicated as "Exercises"). 
In this textbook "exercises" are all mathematical questions proposed for the student to solve at the end of each chapter - all with a high degree of difficulty. In some chapters (II and III) the representation is heavily symbolic (algebraic) with no figures and with a minimum of natural language. The thinking processes required are calculations and translations from natural language to symbolic form (in chapter IV). "Problems" are questions that involve a statement in natural language and may be regarded as just a special kind of exercise.

\subsection{Eduardo Ismael dos Santos Andrea (1924). Compêndio de Álgebra (Algebra} Compendium). This textbook, with 173 pages, was used by $15-16$ year old students. The author was both a university professor (Faculty of Sciences of University of Lisbon) and a high school teacher (Lyceum Pedro Nunes). Chapter VIII has two sections, one on the function $y=a x^{2}-b x+c=0$ and $2^{\text {nd }}$ degree equation in one unknown (6 pp.) and another on properties of the $2^{\text {nd }}$ degree trinomial (13 pp.). Chapter IX deals with $2^{\text {nd }}$ degree problems and their discussion ( $3 \mathrm{pp}$.). This small chapter begins with a paragraph noting that "it is necessary to recognize if the roots of the equation can be solutions of the problem" (p. 110). Then, it solves three problems, one involving daily life (distribution of money by different people), another on geometry (revolution cone), and the third about physics (launching a body upwards). Chapter X studies equations "which solution reduces to a $2^{\text {nd }}$ degree equation" (p. 117), bi-squared and irrational equations.

Chapter IX ends with exercises related to it and to the previous chapter with solutions (4 pp.). The exercises proposed are varied, including questions such as: "Solve the equation" (1-21); "Write the equations with the following roots" (22-25); "Discuss, a priori, the equations" (26-29); "Solve the inequality" (33) and others (figure 4). The set of exercises ends with two problems, both geometrical, one involving a circle and a square and another a sphere and a cylinder (figure 4). It is interesting to note the last somehow unstructured part of the problems' statement (“Discussion”). 


\section{EXERCICES}

Solve the equations:

1. $2 x^{2}-3 x-2=0$

2. $x^{2}+\frac{7}{20} x-\frac{3}{10}=0$

$(\ldots)$

19. $\frac{1}{a}+\frac{1}{b}+\frac{1}{x}=\frac{1}{a+b+x}$

20. $\frac{(a-x)^{2}-(x-b)^{2}}{(a-x)(x-b)}=\frac{4 a b}{a^{2}-b^{2}}$

$(\ldots)$

35. Given a circle of radius $R$ and a line in its plane at a distance $d$ from its center, it is sought to construct a square with side $2 x$, in which one of the sides is a chord of the circle, and which opposite side is in the given line. Discussion.

36. Cut and hemisphere of radius $R$ by a plane parallel to its base, so that the spherical segment of one base obtained has a volume equal to the cylinder which base is the section and which high is the distance of the parallel plans. Discussion.

Figure 4 - First two tasks, two additional tasks and last two tasks from chapter IX.

As in the previous textbook, all tasks proposed at the end of the chapter are called exercises, no matter their difficulty level, the representations are algebraic and in natural language with no figures. Those which statement involves conditions in natural language that must be translated in mathematical language are called "problems". Most the exercises are quite complex and highly structured, requiring calculations. However, in contrast with the 1887 textbook, this one includes two relatively simple exercises (the first two), and one that may be regarded as less structured (requiring the "discussion" of an equation).

\subsection{J. Jorge G. Calado (1960, first edition 1952). Compêndio de Álgebra}

(Compedium of Algebra). The textbook is aimed at lyceum students 12-14 years old and has 419 pages. The author is a teacher in the Normal Lyceum Pedro Nunes. There are two chapters regarding $2^{\text {nd }}$ degree equations and problems. Chapter XX, with 25 pages, has three sections dealing with numerical equations (3 pp.), algebraic solutions (16 pp.), literal equations (2 pp.), and ends with exercises and solutions (5 pp.). Chapter XXI, with 8 pages, is devoted to $2^{\text {nd }}$ degree problems. It includes a section on literal problems - conditions of possibility (4 pp.) and a set of exercises and solutions (3 pp.). 
Chapter XX closes with 8 exercises (with many subquestions) and solutions, including solving $2^{\text {nd }}$ degree numerical and literal equations, first without using the quadratic formula and after using it (figure 5). All exercises are highly structured, from simple to a remarkable complexity. Chapter XXI ends with 33 problems, with varying difficulty, and solutions (figure 6).

\section{EXERCICES}

1. Solve the following equations without using the quadratic formula:
a) $x^{2}-9=0$
b) $4 y=25 \quad x^{2}-9=0$
c) $3 x^{2}-12=0$
d) $7 x^{2}=0,9583(\ldots)$

8. Solve in order to $\mathrm{x}$ the following equations:

(...) $\left.j) \frac{a}{x+a}+\frac{a}{x}+\frac{1}{6}=0 \quad l\right) \frac{a x}{x^{2}-a^{2}}=1+\frac{x}{2 x-2 a}$

Figure 5 - First and last exercises of chapter XX.

\section{EXERCICES}

Solve the following problems:

I) The sum of the inverses of two consecutive whole numbers is equal to $\frac{15}{56}$.

Calculate the numbers (National Exam 1939)

$(\ldots)$

XXXII) The difference between the squares of the diagonals of two rectangles with the same high is equal to $s^{2}$. Calculate the basis of those rectangles knowing that they are for each other as 5 is for 3 .

Figure 6 - First and last problems of chapter XXI.

The representations are algebraic and natural language with no figures. All chapter XX exercises are mathematical, involving solving equations. The exercises at the end of chapter XXI are problems with numerical, geometrical or daily life situations. The processes required are calculations and translations. This textbook has much more exercises than the previous ones and, most specially, also a great increase in the proportion of the simpler tasks.

3.4. António de Almeida Costa, Alfredo Osório dos Anjos and António Augusto Lopes (1974). Compêndio de Matemática (Mathematics compedium). This textbook, with 280 pages, was written by three lyceum teachers to be used by 14 years old lyceum 
students. The topic of $2^{\text {nd }}$ degree equations is presented after the study of logical notions (such as terms and propositions, expressions, conjunction of conditions), the order relation in IR and inequalities. Section 11 deals with numerical $2^{\text {nd }}$ degree equations (12 pp.) and section 12 with $2^{\text {nd }}$ degree problems ( 2 pp.).

Section 11 begins with solving a numerical problem (“I think of a number...”). The problem leads to writing an equation that is solved using the "zero-product property". Next, it presents a new problem and a new equation to solve and then the equation $\left(2 x^{2}+\sqrt{2} x=0\right)$ is solved using such property. The first three points close with four exercises to solve (figure 7). Point 4 includes two new equations $\left(x^{2}-9=0\right.$ and $4 x^{2}-3=0$ ), solved by using special cases of factoring polynomials, and four more exercises. Point 5 solves complete $2^{\text {nd }}$ degree equations using special cases of factoring polynomials, and end with three exercises. The next two points present more examples of solved equations, of increasing complexity, and end with four exercises, all quite simple (figure 7). Point 13 presents the canonical form and the notion of incomplete equation showing how to solve them. The quadratic formula is proved by completing the square and with no use of natural language. Finally, this point presents two solved examples and four exercises to solve. In section 12 the textbook solves four problems by several processes (not always by applying the quadratic formula). The first is a numerical problem, the second involves ages, the third is about buying pencils and notebooks and the fourth is a geometry problem involving a triangle rectangle, highs, legs and hypotenuse. The section closes with five problems to solve and their solutions (figure 8).

\section{Exercises}

(set 1) Solve the following equations:
a) $x^{2}-\sqrt{3} x=0$
b) $x^{2}=4 x$
c) $3^{2}+\sqrt{3} x=0$
d) $5 x^{2}-1.4 x=0$

$(\ldots)$

(set 5) Solve the following equations:
(...) c) $4 x^{2}+9=0$
d) $x^{2}-\frac{5}{6} x+\frac{1}{6}=0$

Figure 7 -First and last sets with exercises in section 11. 
12.5 Solve the following problems:

1) Find to consecutive whole numbers, knowing that the sum of the squares is 61 .

5) The area of a room may be covered by 3000 squared tiles or with 2500 rectangular tiles. Find the dimension of the rectangular tiles knowing that length surpasses width in $2 \mathrm{~cm}$ and this is equal to the squared tiles.

Figure 8 - Proposed problems in section 11.

In this textbook there are few exercises. They are highly structured, requiring calculations or translations, and their difficulty level is low (figures 24-28). The proposed problems are regarded as tasks framed natural language and involve situations from geometry and daily life. An important innovation is that tasks are proposed as the topics are addressed and not at the end of the chapter, as in the former textbooks. Another difference is that problems are no longer presented as a special kind of exercise but as a different task.

3.5. António de Almeida Costa, Alfredo Osório dos Anjos and António Augusto Lopes (1983). Matemática Jovem (Young mathematics). This textbook, written by the same authors, has 327 pages and aimed at 14 year old students. Chapter 5, with 15 pages, addresses $2^{\text {nd }}$ degree equations and problems. The chapter is divided in four parts, beginning with $2^{\text {nd }}$ degree equations in IR ( 8 pp.) and $2^{\text {nd }}$ degree problems $(2 \mathrm{pp}$.$) ,$ followed by several sets of tasks as well as their solutions.

The first part of the chapter begins by solving a problem from which the $2^{\text {nd }}$ degree equation is defined. Next, it solves different kinds of incomplete $2^{\text {nd }}$ degree equations, and then the complete equation factoring special cases, and, finally presents and proves the quadratic formula and applies it in two exercises. In last point it synthetizes the several kinds of $2^{\text {nd }}$ degree equations and its solution and possibility in IR, indicating the simplified quadratic formula. The second part concerns $2^{\text {nd }}$ degree problems, and presents four solved problems, two numerical, one involving relations between ages, and the last one on high, legs and hypotenuse of a right triangle. In the third part, under "complementary activities" the textbook proposes solving nine sets of tasks involving equations and five problems and indicates their solutions. One must note the complexity of the equations presented in the two last points of task 8 and the use of logical symbols in task 9 (figure 9). 
1. Solve the equations in R:

a) $x^{2}-49=0 \quad$ (..) c) $x^{2}=63$ d) $x^{2}+9=0$

$(\ldots)$

8. Solve, in $\mathrm{R}$, the following equations: (...)

i) $\frac{6}{x}-5=x \quad$ j) $x-\frac{3}{x-1}=3$

9. Verify that:

a) $x^{2}+(x+2)^{2}=10^{2}<=>x=6 \vee x=-8$

b) $x(2 x-1)=(x+1)^{2}+3<=>x=4 \vee x=-1$

Figure 9 - Fist and last exercises about the 2nd degree equation.

The chapter ends with a section named "review activities" constituted by questions that involve topics formerly dealt with such as inequalities, systems of equations, factoring polynomials, solving equations, solving problems and simplifying radicals. The number of tasks proposed to the student to solve increased a lot in relation to the previous textbook, and is again put at the end of the chapter - not as simply a list, but as a section on its own right. The tasks are highly structured, framed in algebraic and natural language with no figures, and requiring calculations or translations. One must note that two of the equations proposed have some difficulty, with the unknown in the denominator. The problems are the same as in the previous textbook. An interesting feature of this textbook is that the term "exercise" does not appear, being replaced by the term "activity".

3.6. Maria Augusta F. Neves, Luís Guerreiro and Armando Neves (2004). Matemática 9 (Mathematics 9). This textbook was published in two volumes and aims 14 years old basic education students. One author teaches in a higher education polytechnic and two are secondary school mathematics teachers. The first volume (128 pages) is divided in four chapters, one dealing with $2^{\text {nd }}$ degree equations ( $22 \mathrm{pp}$.). This chapter has four sections, all with 4 pages: (i) Operations with polynomials. Special cases of factoring polynomials. Decomposition in factors; (ii) Solving incomplete $2^{\text {nd }}$ 
degree equations. Zero-product property; (iii) Solving complete $2^{\text {nd }}$ degree equations. Quadratic Formula; and (iv) Solving $2^{\text {nd }}$ degree problems. Half of each section presents an explanation of the topic, several solved examples of related questions and a small synthesis and the other half includes a set of "problems", the last one presented as "reflection/discussion". The chapter ends with a review section named "keywords/knowledge and specific capacities" and another on "evaluation".

The fourth section concerns solving $2^{\text {nd }}$ degree problems. It suggests drawing a diagram to help writing an equation that relates data and unknown. Three problems are solved, two geometrical (one involving an enlargement of area and the other the fencing of a pre-school garden) and one numerical (the product of a number by its third part is 48. What is the number?). The sections ends proposing problems to solve, one numerical, four geometrical, two concerning functions, and one riddle.

The evaluation section has two kinds of tasks - five multiple choice questions (2 pp.) and nine "development questions, including both equations and problems to solve (figures 10 and 11). Most of the tasks are of low complexity. There is no mention to "exercises", but, in contrast, the term "problem" is very frequent. At the end of the textbook solutions for all tasks are provided.

2. Solve each of the following equations without making use of the quadratic formula.
$2.1 x^{2}-9=0$
$2.2(x-5)^{2}=0$
$2.3-x^{2}+7=0$
$2.42 x^{2}=-\frac{1}{2} x$
$2.5(x+3)^{2}=0$
$2.6(x-2)^{2}=9$
$2.7(x-4)^{2}=5$
$2.8 x^{2}-2 x+1=16$

3. Observe the figure.

The volume of the parallelepided that the derrick is pulling is $24 \mathrm{~m}^{2}$.

3.1 Find the dimentions of the parallelepided.

3.2 What is the mass of the parallelepided if $5 \mathrm{~m}^{2}$ of the same material have a mass of $7500 \mathrm{~kg}$ ?



4.For each of the following equations, write it in canonical form and use the quadratic formula to find the solutions. 

$4.12 x^{2}+3 x=-2$
$4.2 x(x+2)=8$
$4.3 x^{2}-\frac{1}{3}=-\frac{2}{3} x$
$4.4 \frac{x-2}{2}-x(x+1)=-19$

Figure 10 - Three of the tasks of higher complexity at the end of the chapter.

9. The space, in meters, travelled by a body in free fall and with no friction is, approximately, $e=5 t^{2}$ where $t$ represents the time, in seconds, since the beginning of the fall.

9.1 A coin was dropped from the top a tower and took 3 seconds to reach the ground. What is the high of the tower?

9.2. A parachutist fell from an airplane in free fall for $720 \mathrm{~m}$. How much time he took to open the parachute?

Figure 11 - Last task at the end of the chapter.

In this textbook, there are tasks to solve in each section and at the end of the chapter. Most tasks are highly structured, require calculations and translations and some also require understanding concepts and interpretation. They are framed in algebraic and natural language with frequent figures and some are purely mathematical (numerical and geometrical) and others draw on daily life situations. One must note that most of the tasks are of low complexity, but they are most often termed as "problems".

\section{Conclusion}

In all manuals, the study of $2^{\text {nd }}$ degree and $2^{\text {nd }}$ degree problems are associated, either in the same chapter, or in contiguous chapters. The main representations are algebraic and natural language, only very recently figures emerged with an important role. Throughout this period, the most common problems are numeric, geometric and daily life, with one or another physics problem. Besides the discourse, we do not see much evolution on these problems, except in the daily life problems, in which we note a remarkable change of themes.

In this set of textbooks there is a very interesting development in the tasks proposed for the students to solve. The questions presented decrease progressively in their complexity and, in addition to calculation and translation of natural to symbolic language, they begin also requiring some understanding of concepts and interpretation 
of situations. Another important evolution concerns the place of tasks in textbooks from the short list at the end of the chapter, to the long list, and finally to its scattering through the chapter.

It should be noted, finally, the resignification process that the terms "exercise" and "problem" assumed over time. At first, the exercises are very complex tasks and problems are a particular type of exercises, with a statement in natural language. Over time, the exercises begin including a wide variety of tasks that, in general, assume less and less complexity. Later, the term "exercise" disappears and is replaced by "activity" and, in the last manual, the more inclusive term that means any type of task is "problem." In this evolution, we note an effect of mathematics education, which devalues the concept of exercise (contributing to its disappearance in textbooks) and values the concept of the problem (contributing towards its visibility).

The tendency to simplify the tasks proposed to students is certainly a consequence of changes in the role of the school, in particular its universalization at increasingly higher levels. The broadening of representations used and the processes required in students is certainly due to a better understanding of their learning processes. But, above all, it is worth mentioning the great capacity of adaptation of textbooks, which appropriate terms used in mathematics education, such as "activity" and "problem", resignifying them according to their own logic.

\section{References}

Andrea, E. I. S., (1924). Compêndio de Álgebra. Lisboa: Imprensa Nacional de Lisboa.

Calado, J. J. G. (1960). Compêndio de Álgebra. Lisboa: Livraria Popular de Francisco Franco.

Costa, A. A., Anjos, A. O. \& Lopes, A. A. (1970). Compêndio de Matemática. Porto: Porto Editora.

Costa, A. A., Anjos, A. O. \& Lopes, A. A. (1987). Matemática Jovem. Porto: Porto Editora.

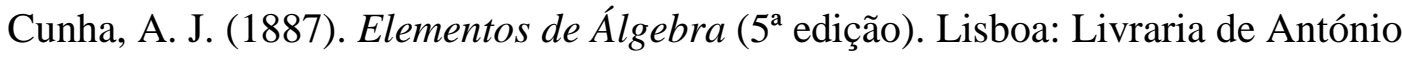
Maria Pereira.

Kilpatrick, J. (1992). A history of research in mathematics education. In D. A. Grouws (Ed.), Handbook of research on mathematics teaching and learning (pp. 3-38). New York: Macmillan. 
Kilpatrick, J., \& Izsák, A. (2008). A histpory of algebra in the school curriculum. In C. E. Greenes \& R. Rubenstein (Eds.), Algebra and algebraic thinking in school mathematics (pp. 3-18). Reston, VA: NCTM.

Neves, M. A. F., Guerreiro, L. \& Neves, A. (2004). Matemática 9 (1 ${ }^{\text {a }}$ edição). Porto: Porto Editora.

OCDE (2004). Learning for Tomorrow's World: First results from PISA 2003. Paris: OCDE.

Pólya, G. (1957). How to solve it: A new aspect of mathematical method ( $2^{\text {nd }}$ ed.). New York, NY: Doubleday.

Ponte, J. P. (2004). As equações nos manuais escolares. Revista Brasileira de História da Matemática, 4(8), 149-170.

Ponte, J. P., \& Abrantes, P. (1982). Os problemas e o ensino da Matemática. In Ensino da Matemática: Anos 80 (pp. 201-214). Lisboa: SPM.

Ponte, J. P., Salvado, C., Fraga, A., Santos, T., \& Mosquito, E. (2007). Equações do 2. ${ }^{\circ}$ grau do fim do século XIX ao início do século XXI: Uma análise de sete manuais escolares. Quadrante, 16(1), 111-145.

Skovsmose, O. (2001). Landscapes of investigation. ZDM, 33(4), 123-132.

Stanic, G. M. A., \& Kilpatrick, J. (1989). Historical perspectives on problem solving in the mathematics curriculum. In R. I. Charles \& E. A. Silver (Eds.), The teaching and assessing of mathematical problem solving (pp. 1-22). Reston, VA: NCTM e Lawrence Erlbaum.

Stein, M. K., \& Smith, M. S. (1998). Mathematical tasks as a framework for reflection: From research to practice. Mathematics Teaching in the Middle School, 3(4), 268-275. 